\title{
Adverse Drug Reaction Reporting in Africa and a Comparison of Individual Case Safety Report Characteristics Between Africa and the Rest of the World: Analyses of Spontaneous Reports in VigiBase ${ }^{\circledR}$
}

\author{
Haggar H. Ampadu ${ }^{1,2} \cdot$ Jarno Hoekman $^{2} \cdot$ Marieke L. de Bruin $^{2} \cdot$ Shanthi N. Pal ${ }^{3} \cdot$ \\ Sten Olsson ${ }^{4} \cdot$ Daniele Sartori $^{4} \cdot$ Hubert G. M. Leufkens $^{2} \cdot$ Alexander N. O. Dodoo $^{1}$
}

Published online: 11 January 2016

(C) The Author(s) 2016. This article is published with open access at Springerlink.com

\begin{abstract}
Introduction Following the start of the World Health Organization (WHO) Programme for International Drug Monitoring (PIDM) by 10 member countries in 1968, it took another 24 years for the first two African countries to join in 1992, by which time the number of member countries in the PIDM had grown to 33. Whilst pharmacovigilance (PV), including the submission of individual case safety reports (ICSR) to VigiBase ${ }^{\circledR}$, the WHO global ICSR database, is growing in Africa, no data have been published on the growth of ICSR reporting from Africa and how the features of ICSRs from Africa compare with the rest of the world (RoW).

Objective The objective of this paper was to provide an overview of the growth of national PV centres in Africa, the reporting of ICSRs by African countries, and the features of ICSRs from Africa, and to compare ICSRs from Africa with the RoW.

Methods The search and analysis interface of VigiBase ${ }^{\circledR}$ - VigiLyze ${ }^{\circledR}$ - was used to characterise ICSRs submitted by African countries and the RoW. The distribution of ICSRs by African countries was listed and characterised by anatomic therapeutic chemical (ATC) code, Medical Dictionary for Regulatory Activities
\end{abstract}

Haggar H. Ampadu

haggar.ampadu@who-pvafrica.org

1 WHO Collaborating Centre for Advocacy and Training in Pharmacovigilance, School of Medicine and Dentistry, University of Ghana, P.O Box GP 4236, Accra, Ghana

2 Utrecht Institute for Pharmaceutical Sciences, Utrecht University, Utrecht, The Netherlands

3 Safety and Vigilance, World Health Organization, Geneva, Switzerland

4 Uppsala Monitoring Centre, Uppsala, Sweden $\left(\right.$ MedDRA $^{\circledR}$ ) system organ class (SOC) classification, and patient age and sex. The case-defining features of ICSRs between Africa and the RoW were also compared.

Results The number of African countries in the PIDM increased from 2 in 1992 to 35 at the end of September 2015, and African PIDM members have cumulatively submitted 103,499 ICSRs (0.88 \% of global ICSRs) to VigiBase ${ }^{\circledR}$. The main class of products in African ICSRs are nucleoside and nucleotide reverse transcriptase inhibitors $(14.04 \%)$, nonnucleoside reverse transcriptase inhibitors $(9.09 \%)$, antivirals for the treatment of HIV infections (5.50\%), combinations of sulfonamides and trimethoprim $(2.98 \%)$ and angiotensin-converting enzyme (ACE) inhibitors $(2.42 \%)$. The main product classes implicated in ICSRs from the RoW are tumour necrosis factor- $\alpha(\mathrm{TNF} \alpha)$ inhibitors (5.29\%), topical nonsteroidal anti-inflammatory preparations $(2.26 \%)$, selective immunosuppressants (2.08\%), selective serotonin reuptake inhibitors $(2.04 \%)$ and HMG CoA reductase inhibitors $(1.85 \%)$. The main SOCs reported from Africa versus the RoW include skin and subcutaneous tissue disorders (31.14\% vs. $19.58 \%)$, general disorders and administration site conditions (20.91\% vs. $30.49 \%)$ and nervous system disorders $(17.48 \%$ vs. $19.13 \%)$. The 18-44 years age group dominated ICSRs from Africa, while the 45-64 years age group dominated the RoW. Identical proportions of females (57\% Africa and the RoW) and males (37\% Africa and the RoW) were represented.

Conclusions As at the end of September 2015, 35 of 54 African countries were Full Member countries of the PIDM. Although the number of ICSRs from Africa has increased substantially, ICSRs from Africa still make up $<1 \%$ of the global total in VigiBase ${ }^{\circledR}$. The features of ICSRs from Africa differ to those from the RoW in relation to the classes of products as well as age group of patients affected. The gender of patients represented in these ICSRs are identical. 


\section{Key Points}

As at the end of September 2015, 35 African countries were Full Members of the WHO Programme for International Drug Monitoring.

The 35 countries from Africa have submitted $103,499(0.88 \%)$ of the global total of $11,824,804$ ICSRs in VigiBase ${ }^{\circledR}$ submitted by all 122 members of the PIDM.

ICSRs from Africa differ from the rest of the world in relation to the classes of products implicated and the age of patients.

\section{Introduction}

Pharmacovigilance (PV) is a relatively new science and public health activity in most African countries compared with industrialised countries. Before the year 2000, PV was not a priority in Africa due to several factors, including poor legislation for medicines regulation, lack of access to medicines and health commodities, weak and uncoordinated supply chains for medical products, lack of knowledge and awareness of PV, and lack of financial, human and technical resources for PV [1-3]. Access to medicines in Africa for managing priority communicable diseases such as HIV/AIDS, malaria and tuberculosis has increased since 2000 due to concerted global efforts. In addition, the emerging middle class are able to pay out of pocket for their medical care, especially in relation to noncommunicable diseases. The increased access to medicines and health commodities has shifted the national development agenda towards safe and cost effective use of these products and the establishment of surveillance systems for their safety, effectiveness and quality. National PV systems are therefore now beginning to emerge in Africa.

Globally, the existence of formal national PV systems is indicated by participation in the WHO Programme for International Drug Monitoring (PIDM). Membership of the $\mathrm{PIDM}$ is based on the existence of a designated national PV centre, a spontaneous adverse drug reaction (ADR) reporting system, and the demonstration of technical competence in managing individual case safety reports (ICSRs) by submitting at least 20 ICSRs to the global ICSR database, VigiBase ${ }^{\circledR}$, maintained by the Uppsala Monitoring Centre (UMC), Sweden, on behalf of the World Health Organization (WHO) [http://who-umc.org/graphics/ 24730.pdf]. The PIDM started with 10 members in 1968 following the thalidomide tragedy, and as of September
2015 had 122 Full Member countries, with 29 Associate Members awaiting full membership while compatibility between their national format and the international reporting formats is being established. ICSR reporting to VigiBase ${ }^{\circledR}$ is a useful indicator to measure and compare the national PV activity of countries, but it is important to highlight that PV is not just about spontaneous reporting and ICSR collection and submission; it involves several other surveillance, clinical and product quality assessment activities, including active PV and pharmacoepidemiological studies, medication error monitoring and the detection of products with compromised pharmaceutical integrity, including counterfeit and substandard medicines.

Although the PIDM started in 1968, the first African countries joined in 1992, and by 30 September 2015 a total of 35 of 54 African countries were Full Members of the PIDM. As yet, no comprehensive data have been published on PV, including ICSR reporting in Africa. A recent article by Isah et al. [3] provided a broad overview of the specific features and challenges of PV in Africa and identified the following constraints: weak human and material resources, poor training, irrational use of medicines, circulation of counterfeit medicines, high consumption of herbal medicines and weak pharmaceutical sector regulation. In terms of ICSR reporting in Africa, Berhe et al. recently [4] examined the data in VigiBase ${ }^{\circledR}$ and noticed important differences in adverse drug reaction (ADR) reports for cardiometabolic drugs between Africa and the rest of the world (RoW). In particular, they noted differences in the age groups of patients, as well as higher reporting of ADRs to angiotensin-converting enzyme (ACE) inhibitors in African ICSRs compared with the RoW. The reasons behind such differences are important to ascertain as they may have implications for product and patient safety; however, the paucity of publications on PV in Africa makes this difficult. Researchers are therefore focusing on assessing the PV infrastructure in low- and middle-income countries [5] and how PV is being undertaken in important public health programmes such as malaria [6], HIV [7] and tuberculosis [8].

In view of the increasing number of African countries joining the PIDM and submitting data to VigiBase ${ }^{\circledR}$, there is a need to understand the features of PV in Africa, including the main ICSR reporting countries, the number and types of ICSRs being submitted to the PIDM, the classes of products implicated in these ICSRs and the types of events reported. This work was therefore undertaken to provide information on the current PV situation in Africa, specifically ICSR reporting in Africa. Its main goal was to provide an overview of reporting activities in Africa and to compare the characteristics of ICSRs from Africa with those from the RoW. This will provide needed data to 
evaluate the progress of PV in Africa and give the WHO, national governments, the pharmaceutical industry and funding organisations a picture of PV in Africa.

\section{Objectives}

The objectives of this work were to characterise ICSR reporting activities in Africa and to compare them with the RoW by (i) documenting the development of PV in Africa in terms of countries joining the WHO PIDM; (ii) assessing the reporting of ICSRs to VigiBase ${ }^{\circledR}$ by national PV centres in Africa and identifying the top reporting countries; (iii) determining the main product classes, the main ADRs and the demographic features of African ICSRs and comparing these with the RoW.

\section{Methods}

\subsection{Data Source}

The data source utilised in this quantitative study was VigiBase $^{\circledR}$, the global ICSR database [9]. VigiBase ${ }^{\circledR}$ contains more than 11 million individual case reports of suspected ADRs submitted since 1968 by the 122 member countries of the WHO Programme. It represents the official and most authoritative data source for ICSR reporting globally. VigiBase ${ }^{\circledR}$ contains ICSR data on conventional medicines and traditional medicines (herbals), as well as biological products and vaccines.

\subsection{Data Analysis}

Quantitative data analysis was undertaken on the number of ICSRs submitted by each African country, as well as the types of products and ADRs in these ICSRs. These data were extracted from VigiBase ${ }^{\circledR}$. Similar analysis was also undertaken for the RoW. ICSRs from Swaziland, who became members in 2015, are not included in the cumulative counts since they were entered closer to the data analysis cutoff date (30 September 2015) and are yet to be incorporated into the analysis section of VigiBase ${ }^{\circledR}$. The analysis was performed by using the search and analysis interface of VigiBase ${ }^{\circledR}$, known as VigiLyze ${ }^{\circledR}$, and Microsoft SQL queries. Using the query interface with predefined filters, data were pulled on reporting statistics, substances or products and ICSRs in a line listing report output. These queries were then saved and the output exported to Microsoft Excel ${ }^{\mathrm{TM}}$ (Microsoft Corporation, Redmond, WA, USA). The year of joining the WHO Programme as
Full Members by individual countries was obtained from the website of the WHO PIDM, the UMC (http://www. who-umc.org), and the population of each country per year was obtained from the United Nations (http://www.unfpa. org/swop). The population for each year was summed from the year they joined the programme, in order to obtain the cumulative population, which was then used for the calculations below.

The ICSR data were normalised to take into account the length of time a country has been in the PIDM, as well as the population size, by expressing the ICSRs as number of reports per million person-years. In order to know the main product classes implicated in ICSRs, all products reported as suspected of causing a reaction were aggregated on the fourth-level ATC code, and the number of times a product class was reported was counted. Combination products, by definition, ended up being counted in terms of their individual components so the number of individual active substances and ATC codes may be more than the number of products. Since a few active ingredients have more than one ATC code, the total number of product classes expressed may be slightly higher than the actual number of classes submitted in the submitted ICSRs but this is unavoidable. The ADRs in the ICSRs were identified by aggregating coded ADRs in each ICSR using the Medical Dictionary for Regulatory Activities (MedDRA ${ }^{\circledR}$ ) system organ class (SOC) classification. The age and gender of patients in each ICSR were extracted and aggregated for both Africa and the RoW.

\section{Results}

\subsection{Growth of National Pharmacovigilance (PV) Centres and Reporting of ICSRs in Africa}

The 35 African countries who are Full Members of the PIDM, their year of joining and the number of reports (ICSRs) they have submitted since joining the PIDM are shown in Table 1. Morocco and South Africa were the first to join in 1992, followed by Tanzania and Tunisia in 1993 and Zimbabwe in 1998. Ten other African countries joined the PIDM from 2000 to 2008 , after which there was a sharp increase in membership, with 18 countries joining the PIDM in the 5-year period from 2010 to 2015 .

Reporting of ICSRs from Africa is extremely low compared with the RoW, with the cumulative number of ICSRs from Africa to VigiBase ${ }^{\circledR}$ standing at 103,499 ICSRs, which is equivalent to $0.88 \%$ of the global total number of $11,824,804$ ICSRs in VigiBase ${ }^{\circledR}$ at 30 September 2015. The main ICSR reporting countries in Africa in 
Table 1 Full members of the Programme for International Drug Monitoring in Africa
Country Year of joining No. of ICSRs to 2015 No. of ICSRs per million person years ${ }^{\mathrm{a}}$

\begin{tabular}{|c|c|c|c|}
\hline Angola & 2013 & 239 & 5.48 \\
\hline Benin & 2011 & 29 & 0.71 \\
\hline Botswana & 2009 & 103 & 8.60 \\
\hline Burkina Faso & 2010 & 76 & 0.92 \\
\hline Cameroon & 2010 & 46 & 0.42 \\
\hline Cape Verde & 2012 & 247 & 165.67 \\
\hline Congo, the Democratic Republic of & 2010 & 5558 & 16.90 \\
\hline Côte d'Ivoire & 2010 & 28 & 0.28 \\
\hline Egypt & 2002 & 8474 & 8.62 \\
\hline Eritrea & 2012 & 1982 & 104.31 \\
\hline Ethiopia & 2008 & 803 & 1.28 \\
\hline Ghana & 2001 & 2900 & 9.07 \\
\hline Guinea & 2013 & 31 & 1.30 \\
\hline Kenya & 2010 & 8440 & 39.07 \\
\hline Liberia & 2013 & 42 & 4.83 \\
\hline Madagascar & 2009 & 1087 & 8.23 \\
\hline Mali & 2011 & 80 & 1.33 \\
\hline Mauritius & 2014 & 39 & 31.22 \\
\hline Morocco & 1992 & 17,231 & 25.38 \\
\hline Mozambique & 2005 & 797 & 3.36 \\
\hline Namibia & 2009 & 1604 & 119.25 \\
\hline Niger & 2012 & 39 & 0.72 \\
\hline Nigeria & 2005 & 10,590 & 6.70 \\
\hline Rwanda & 2013 & 29 & 1.21 \\
\hline Senegal & 2009 & 181 & 2.44 \\
\hline Sierra Leone & 2008 & 1272 & 30.97 \\
\hline South Africa & 1992 & 28,609 & 27.22 \\
\hline Sudan & 2009 & 38 & 0.20 \\
\hline Swaziland & 2015 & 27 & 19.02 \\
\hline Tanzania, United Republic of & 1993 & 1360 & 1.68 \\
\hline Togo & 2008 & 311 & 6.86 \\
\hline Tunisia & 1993 & 6990 & 32.14 \\
\hline Uganda & 2008 & 1871 & 7.59 \\
\hline Zambia & 2010 & 218 & 3.09 \\
\hline Zimbabwe & 1998 & 2155 & 9.77 \\
\hline
\end{tabular}

ICSRs individual case safety reports

${ }^{\text {a }}$ Data from VigiBase ${ }^{\circledR}$ to 30 September 2015. Cumulative population to 2014 was used as 2015 data were not yet available terms of cumulative data in VigiBase ${ }^{\circledR}$ include South Africa, Morocco, Nigeria, Egypt and Kenya (Table 2). South Africa, Morocco and Nigeria alone account for more than half of the African ICSRs in VigiBase ${ }^{\circledR}$. When the ICSRs are expressed per million person-years (Table 1), which normalises ICSRs to take into account population size as well as the length of time a country has been in the PIDM, the top countries included Cape Verde, Namibia, Eritrea, Kenya, Tunisia, South Africa and Morocco.

\subsection{Product Classes Implicated in Individual Case Safety Reports (ICSRs) from Africa and the Rest of the World (RoW)}

The main product classes implicated in ICSRs from Africa are shown in Table 3, which is dominated by classes of products for treating HIV/AIDS, namely nucleoside and nucleotide reverse transcriptase inhibitors (14.04\%), nonnucleoside reverse transcriptase inhibitors $(9.09 \%)$, and 
Table 2 Main African reporting countries

\begin{tabular}{lcl}
\hline Country & $\begin{array}{l}\text { No. of ICSRs } \\
\text { in VigiBase }\end{array}$ & $\begin{array}{l}\text { Percentage of total } \\
\text { African ICSRs }^{\mathrm{a}} \text { in } \\
\text { VigiBase }^{\circledR}\end{array}$ \\
\hline South Africa & 28,609 & 27.64 \\
Morocco & 17,231 & 16.65 \\
Nigeria & 10,590 & 10.23 \\
Egypt & 8474 & 8.19 \\
Kenya & 8440 & 8.15 \\
Tunisia & 6990 & 6.75 \\
Congo, the Democratic & 5558 & 5.37 \\
$\quad$ Republic of & & \\
Ghana & 2900 & 2.80 \\
Zimbabwe & 2155 & 2.08 \\
Eritrea & 1982 & 1.91 \\
\hline
\end{tabular}

ICSRs individual case safety reports

a Total ICSRs from all African countries to 30 September 2015 (excluding Swaziland, $n=27$ ) was 103,499

antivirals for treatment of HIV infections (5.50\%). Others include combinations of sulfonamides and trimethoprim, including derivatives $(2.98 \%)$, ACE inhibitors, plain $(2.42 \%)$, antibiotics $(2.26 \%)$, meningococcal vaccines $(2.23 \%)$, interferons $(2.06 \%)$ and combination products for tuberculosis $(1.87 \%)$. In contrast to African ICSRs, there is no single dominant product class in RoW reports (Table 4). The classes of products commonly reported in ICSRs from the RoW (Table 4) include tumour necrosis factor- $\alpha(\mathrm{TNF} \alpha)$ inhibitors (5.29\%), anti-inflammatory preparations, nonsteroids for topical use (2.26\%), selective immunosuppresants $(2.08 \%)$, selective serotonin reuptake inhibitors $(2.04 \%)$, and HMG CoA reductase inhibitors $(1.85 \%)$.

\subsection{Adverse Drug Reactions (ADRs) in ICSRs from Africa and the RoW}

In SOC classification, African ICSRs are dominated by reports of skin and subcutaneous tissue disorders $(31.14 \%)$, general disorders and administration site conditions $(20.91 \%)$, nervous system disorders $(17.48 \%)$ and gastrointestinal disorders $(16.10 \%)$, as shown in Table 5 . These are followed by respiratory, thoracic and mediastinal disorders $(5.71 \%)$, investigations $(5.07 \%)$, blood and lymphatic system disorders $(5.04 \%)$, psychiatric disorders $(4.72 \%)$, musculoskeletal and connective tissue disorders $(4.36 \%)$ and infections and infestations $(3.78 \%)$. The main ADRs in the RoW reports (Table 6) are not dissimilar from those reported in Africa and include general disorders and administration site conditions (30.49\%), skin and connective tissue disorders $(19.58 \%)$, nervous system disorders $(19.13 \%)$, and gastrointestinal disorders $(17.86 \%)$.

\subsection{Patient Characteristics: Africa vs. the RoW}

The dominant age group from Africa was 18-44 years $(39.10 \%)$ compared with the RoW, which is dominated by an older age group of 45-64 years (24.13\%) (Fig. 1). A significant proportion of reports from both Africa $(16.18 \%)$ and the RoW (26.00\%) failed to mention the age group of those affected, highlighting the incompleteness of a good number of ICSRs submitted to VigiBase $^{\circledR}$. The gender of patients in African and RoW ICSRs are identical for females (57\% Africa vs. $57 \%$ RoW) and males (37\% Africa vs. $37 \%$ RoW). Six percent of reports from both Africa and the RoW did not specify the gender.
Table 3 Top 10 product classes in African reports vs. RoW reports

\begin{tabular}{|c|c|c|}
\hline ATC code & Africa $(\%)^{\mathrm{a}}$ & $\operatorname{RoW}(\%)^{\mathrm{b}}$ \\
\hline J05AF-nucleoside and nucleotide reverse transcriptase inhibitors & $14,530(14.04)$ & $44,055(0.38)$ \\
\hline J05AG-non-nucleoside reverse transcriptase inhibitors & $9407(9.09)$ & $26,107(0.22)$ \\
\hline J05AR - antivirals for the treatment of HIV infections, combinations & $5692(5.50)$ & $34,927(0.30)$ \\
\hline $\begin{array}{l}\text { J01EE-combinations of sulfonamides and trimethoprim, incl. } \\
\text { derivatives }\end{array}$ & $3082(2.98)$ & $81,206(0.69)$ \\
\hline C09AA-ACE inhibitors, plain & $2503(2.42)$ & $154,176(1.32)$ \\
\hline S01AA—antibiotics & $2340(2.26)$ & $179,635(1.53)$ \\
\hline J07AH—meningococcal vaccines & $2308(2.23)$ & $48,480(0.41)$ \\
\hline L03AB_-interferons & $2130(2.06)$ & $211,098(1.80)$ \\
\hline J04AM-combinations of drugs for treatment of tuberculosis & $1933(1.87)$ & $7043(0.06)$ \\
\hline D06AX - other antibiotics for topical use & $1855(1.79)$ & $103,228(0.88)$ \\
\hline
\end{tabular}

RoW rest of the world, ATC anatomic therapeutic chemical, ACE angiotensin-converting enzyme, ICSRs individual case safety reports

${ }^{\text {a }}$ Percentage includes all African ICSRs $(n=103,499)$ in VigiBase ${ }^{\circledR}$ (excluding Swaziland, $n=27$ )

b Percentage of all RoW ICSRs $(n=11,721,305)$ in VigiBase ${ }^{\circledR}$ 
Table 4 Top 10 product classes in RoW reports vs. African reports

Table 5 Top 10 SOCs in African reports vs. RoW reports

Table 6 Top 10 SOCs in RoW reports vs. African reports

\begin{tabular}{lrr}
\hline ATC code & RoW $(\%)^{\mathrm{a}}$ & ${\text { Africa }(\%)^{\mathrm{b}}}^{\mathrm{a}}$ \\
\hline L04AB - tumour necrosis factor alpha inhibitors & $619,737(5.29)$ & $939(0.91)$ \\
M02AA—-antiinflammatory preparations, non-steroids for topical use & $265,138(2.26)$ & $1350(1.30)$ \\
L04AA-selective immunosuppressants & $243,382(2.08)$ & $238(0.23)$ \\
N06AB-selective serotonin reuptake inhibitors & $238,611(2.04)$ & $718(0.69)$ \\
C10AA-HMG CoA reductase inhibitors & $217,302(1.85)$ & $936(0.9)$ \\
M01AE-propionic acid derivatives & $214,595(1.83)$ & $738(0.71)$ \\
L03AB-interferons & $211,098(1.80)$ & $2130(2.06)$ \\
N05AH-diazepines, oxazepines, thiazepines and oxepines & $205,773(1.76)$ & $650(0.63)$ \\
N06AX-other antidepressants & $201,461(1.72)$ & $1398(1.35)$ \\
N03AX-other antiepileptics & $187,813(1.60)$ & $959(0.93)$
\end{tabular}

RoW rest of the world, ATC anatomic therapeutic chemical, ICSRs individual case safety reports

${ }^{\text {a }}$ Percentage of all RoW ICSRs $(n=11,721,305)$ in VigiBase ${ }^{\circledR}$

b Percentage of all African ICSRs $(n=103,499)$ in VigiBase ${ }^{\circledR}$ (excluding Swaziland, $n=27$ )

\begin{tabular}{lcr}
\hline SOC & Africa $(\%)^{\mathrm{a}}$ & RoW $(\%)^{\mathrm{b}}$ \\
\hline Skin and subcutaneous tissue disorders & $32,225(31.14)$ & $2,295,539(19.58)$ \\
General disorders and administration site conditions & $21,642(20.91)$ & $3,574,082(30.49)$ \\
Nervous system disorders & $18,094(17.48)$ & $2,242,378(19.13)$ \\
Gastrointestinal disorders & $16,662(16.10)$ & $2,093,534(17.86)$ \\
Respiratory, thoracic and mediastinal disorders & $5912(5.71)$ & $1,046,599(8.93)$ \\
Investigations & $5245(5.07)$ & $1,080,507(9.22)$ \\
Blood and lymphatic system disorders & $5219(5.04)$ & $523,173(4.46)$ \\
Psychiatric disorders & $4890(4.72)$ & $1,042,390(8.89)$ \\
Musculoskeletal and connective tissue disorders & $4512(4.36)$ & $905,026(7.72)$ \\
Infections and infestations & $3912(3.78)$ & $846,842(7.22)$ \\
\hline
\end{tabular}

SOC system organ class, RoW rest of the world, ICSRs individual case safety reports

${ }^{\text {a }}$ Percentage of all African ICSRs $(n=103,476)$ in VigiBase ${ }^{\circledR}$ (excluding Swaziland, $n=27$ )

b Percentage of all RoW ICSRs $(n=11,721,305)$ in VigiBase ${ }^{\circledR}$

\begin{tabular}{llc}
\hline SOC & RoW $(\%)^{\mathrm{a}}$ & Africa $(\%)^{\mathrm{b}}$ \\
\hline General disorders and administration site conditions & $3,574,082(30.49)$ & $21,631(20.91)$ \\
Skin and subcutaneous tissue disorders & $2,295,539(19.58)$ & $32,225(31.14)$ \\
Nervous system disorders & $2,242,378(19.13)$ & $18,094(17.48)$ \\
Gastrointestinal disorders & $2,093,534(17.86)$ & $16,662(16.10)$ \\
Investigations & $1,080,507(9.22)$ & $5245(5.07)$ \\
Respiratory, thoracic and mediastinal disorders & $1,046,599(8.93)$ & $5912(5.71)$ \\
Psychiatric disorders & $1,042,390(8.89)$ & $4890(4.72)$ \\
Injury, poisoning and procedural complications & $946,308(8.07)$ & $3008(2.91)$ \\
Musculoskeletal and connective tissue disorders & $905,026(7.72)$ & $4512(4.36)$ \\
Infections and infestations & $846,842(7.22)$ & $3912(3.78)$ \\
\hline
\end{tabular}

SOC system organ class, RoW rest of the world, ICSRs individual case safety reports

${ }^{\text {a }}$ Percentage of all RoW ICSRs $(n=11,721,305)$ in VigiBase ${ }^{\circledR}$

b Percentage of all African ICSRs $(n=103,499)$ in VigiBase ${ }^{\circledR}$ (excluding Swaziland, $n=27$ ) 


\section{Discussion}

\subsection{Growth of PV in Africa and Features of ICSR Reporting to VigiBase $^{\circledR}$}

Africa was a late comer to global PV, with the first countries becoming involved 24 years after the PIDM started. Whilst the 24-year gap raises troubling questions as to the types of vaccine and medicine safety incidents that may have gone unrecorded, the fact remains that in 2015 there are still 21 African countries who are not members of the PIDM. The growth of African PV in terms of countries joining the PIDM started more as a trickle than a concerted continental effort. From 1992 to 2000, there were only five African members of the PIDM before membership gathered pace in the new millennium. Why did it take so long for African countries to start joining the PIDM and what were the factors underlying this movement? The factors are many and diverse and some authors have mentioned important health system obstacles to PV growth in Africa, including weak overall national health infrastructure and systems, poor understanding of PV, lack of PV in the formal curriculum and low interest by healthcare professionals [10-14]. The steady growth in PIDM membership from 2000 could be due to several factors. The Millennium Development Goals and its focus on health improvement, as well as prevention of infant and maternal mortality, firmly shifted the development agenda to healthcare delivery and health system strengthening in poor countries. The establishment of the Global Fund against HIV/AIDS, Tuberculosis and Malaria (Global Fund), as well as other important global health initiatives (US President's Emergency Plan for Aids Relief [PEPFAR], US President's Malaria Initiative, the Bill and Melinda Gates Foundation, etc.) brought in huge financial resources that enhanced access to medicines [15]. With increased access to medicines, the need to monitor their safety became obvious. The Global Fund, for instance, insisted on safety monitoring of all its products as a key requirement for grant recipients as early as 2002, although research indicates that this was only partially adhered to [16], with improved adherence occurring only after the Fund included a mandatory field relating to $\mathrm{PV}$ on all grant application forms in 2010. The WHO in Geneva, as well as the UMC in Sweden and the WHO Collaborating Centre for PV in Rabat, Morocco, undertook a focused approach on PV capacity building in Africa, with the UMC alone training 100 Africans since 1993 in its annual PV course. The United States Agency for International Development (USAID), working in particular with Management Sciences for Health (MSH), also supported PV activities in Africa. However, the most direct impact on countries joining the PIDM comes from the establishment of an African hub to lead PV development on the continent. In June 2009, the UMC established an African office (UMCAfrica) with dedicated funding, while the WHO designated the University of Ghana (October 2009) as a WHO Collaborating Centre for Advocacy and Training in Pharmacovigilance (WHO-CC), working hand-in-hand with UMC-Africa. The African hub (WHO-CC, UMC-Africa) undertook advocacy, country visits, in-country training and capacity building in several countries, culminating in most of them becoming full members of the PIDM. The rapid increase in African countries joining the PIDM since 2009 is due mainly to this focused continental effort.

In relation to ICSR reporting to VigiBase ${ }^{\circledR}$, the data suggest that nearly one-third of the countries in Africa submit enough data (at least 20 ICSRs) to gain membership
Fig. 1 Age graphs for Africa and the RoW from 1992 to 30 September 2015. RoW rest of the world

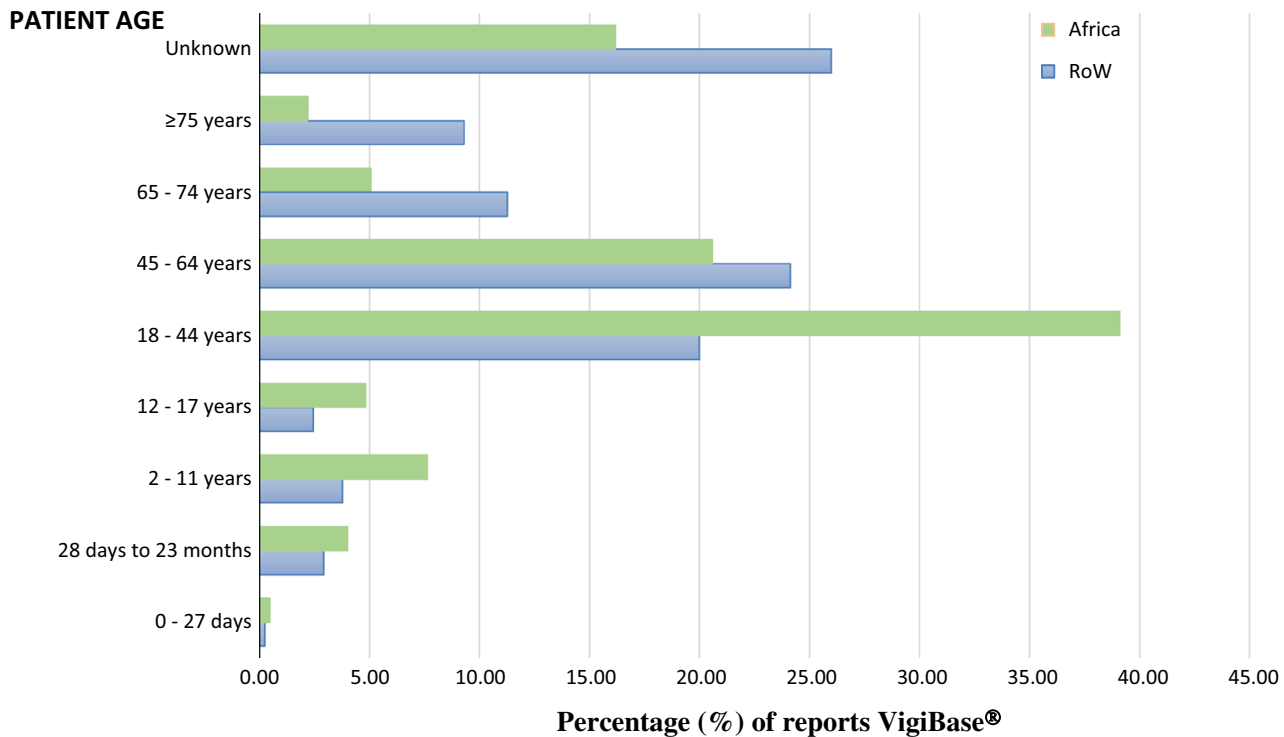


of the PIDM, after which there is a pause-currently 10 countries have submitted less than 100 ICSRs to VigiBase ${ }^{\circledR}$. Poor reporting of ICSRs hinders signal generation. However, for sustainable PV systems, reporting and signal generation needs to be embedded in wider health system-related policies and infrastructures, and this is currently not the case in many countries. For instance, a 2009 survey of PV in 46 sub-Saharan African countries [17] showed that less than half have a national policy that covers PV and $72 \%$ do not have a legal mandate to monitor medicine-related adverse events. Furthermore, only $39 \%$ have national PV guidelines or a national safety advisory committee, and only $28 \%$ have a platform or strategy to coordinate PV at the national level. While African membership of the PIDM has increased, the poor reporting of ICSRs is an indication that health system issues have not been adequately dealt with. Another survey might be necessary to identify appropriate interventions for improving ICSR reporting in Africa. Africa's population of over 1 billion (15\% of the global total) and its healthcare features (high number of infectious diseases, e.g. HIV/ AIDS, tuberculosis, malaria, etc., and increasing incidence of noncommunicable diseases) means that the population is exposed to a high number of medical products, which should theoretically translate to high ICSR reporting. The low number of ICSRs ( $<1 \%$ of ICSRs in VigiBase $\left.{ }^{\circledR}\right)$ is an indication of weak PV activity, especially when one considers the fact that several of the priority diseases in Africa are managed through formal, reasonably well-funded public health programmes that administer large numbers of medicines to millions of individuals annually. The relatively high ICSR reporting countries in Africa appear to be those with an active pharmaceutical industry presence or strong public health programmes.

\subsection{Classes of Products Implicated in ICSRs from Africa}

The main product classes implicated in ICSRs are antiinfectives, notably antiretrovirals and antibiotics. The domination of HIV/AIDS products in African ICSRs is perhaps not surprising considering the high burden of HIV/ AIDS on the continent. With well-funded programmes providing access to antiretrovirals, it is expected that there would be more ICSRs on these products since healthcare workers in these programmes tend to be trained in PV. Indeed, most published PV studies from Africa tend to be on the safety of antiretrovirals [18, 19]. The relatively high number of reports to ACE inhibitors may be an indication of the changing morbidity patterns on the continent with a steeply increasing burden of communicable diseases, in addition to the persisting dominance of noncommunicable diseases as noted and reported by the WHO, the UN and several other players [20-22]. It is interesting to note that the article by Berhe et al. [4], which examined ADRs to cardiometabolic drugs, found a disproportionately higher reporting of ADRs to ACE inhibitors when comparing ICSRs from sub-Saharan Africa with the RoW (36\% vs. $14 \%$ ). Differences such as these underscore the importance of improving ICSR reporting from Africa in order to improve the chances of detecting any African-specific safety issues. The presence of the meningococcal vaccine among the top product classes implicated in African ICSRs may be due to the recent large-scale roll out of the meningococcal vaccine across West Africa in response to outbreaks. This particular programme was accompanied by a concerted PV effort. The vaccines that are widely used in national childhood immunisation programmes in Africa did not feature among the main product categories reported, a strong suggestion that systems for monitoring adverse events following immunization may be absent or that national expanded programmes on immunization do not submit safety data to national PV centres and to VigiBase ${ }^{\circledR}$.

\subsection{Main ADRs in African ICSRs}

The main SOC reported in African ICSRs relate to the expected ADRs of the product classes in African ICSRs. General disorders, skin and appendage disorders and nervous system disorders are among the most frequent and easily identifiable event types reported to antiretrovirals and antibiotics. The presence of 'investigations' among the ADRs in African ICSRs could be due to the public health programmes which provide routine laboratory investigations as part of standard care since laboratory investigations are rarely carried out in routine care in Africa due to cost considerations. Representing the ADRs reported as SOCs does not provide the ability to distinguish the individual ADRs ('Preferred Terms', or PTs) reported. Whilst this was not the focus of the current work, the article by Berhe et al. [4] revealed higher reporting of certain ADRs when expressed as PTs (e.g. lip swelling, cough, angioedema) and little of others (e.g. death, myocardial infarction, congestive cardiac failure) when data from Africa are compared with the RoW, an indication once again of the ability of ICSRs to reveal safety differences between Africa and the RoW.

\subsection{Features of ICSRs: Africa vs. the RoW}

There is a difference in the product classes implicated in ICSRs from Africa compared with the RoW. Several factors could account for this, including differences in disease patterns and prescriptions, differences in PV systems and ADR reporting, and differences in health systems and health literacy, amongst others. These issues are impossible 
to determine from analyses of VigiBase ${ }^{\circledR}$ data. However, an extremely important fact that VigiBase ${ }^{\circledR}$ reveals is that reporting from Africa is extremely low, even for diseases that are more prevalent in Africa. For instance, there were three- to sixfold more ICSRs to nucleoside reverse transcriptase inhibitors, non-nucleotide reverse transcriptase inhibitors and combination antivirals in the RoW than in Africa, even though many more millions of these products are used in Africa than in the RoW. A similar situation occurred in relation to the reporting of ICSRs to antimalarials, as noted by Kuemmerle et al. [6]. ICSRs from the RoW were not dominated by any one class of products, an indication of a PV system that looks at all prevailing conditions and medicines used in their management rather than only products for 'public health programmes'. Thus, while antiretrovirals form the top three product classes in African ICSRs and account for more than $30 \%$ of African reports, the three main product classes from the RoW are $\mathrm{TNF} \alpha$ inhibitors, topical nonsteroidal anti-inflammatory agents and selective immunosuppresants. These three product classes account for $9.63 \%$ of all RoW ICSRs. The only product class that was among the top 10 from both Africa and the RoW are interferons (2130 vs. 211,098 ICSRs), an interesting observation considering their usage in a wide range of conditions, including HIV/AIDS-related Kaposi's sarcoma, leukaemia, hepatitis B, and multiple sclerosis, amongst others. HMG CoA reductase inhibitors (statins), antidepressants, nonsteroidal anti-inflammatory drugs and benzodiazepines are poorly represented in African ICSRs. This is not due to the absence of conditions such as hypercholesterolemia, depression, inflammation, insomnia and epilepsy in Africa. Rather, it seems to reflect poor reporting of ICSRs and/or poor prescriptions for products to deal with these conditions, or both. For instance, the work by Berhe et al. [4] found poor reporting of ICSRs to statins, with all but two ICSRs to statins coming from one country (South Africa), which Berhe et al. inferred to probably be due to a focused PV activity by the manufacturer. The main product class implicated in the RoW ICSRs are TNF $\alpha$ inhibitors (including monoclonal antibodies), which are indicated for a wide range of serious life-threatening conditions and are widely used. Several are marketed with 'black-box' warnings requiring reporting of all events to national regulatory agencies. $\mathrm{TNF} \alpha$ inhibitors are unlikely to be used by large numbers of people in Africa due to their high cost, and this may explain why they do not feature among the top product classes in African ICSRs.

The only difference in the demography of patients in ICSRs from Africa and the RoW is in relation to age. The subgroup analysis of cardiometabolic drugs undertaken by Berhe et al. [4] found the same difference, which is not surprising considering that the population in Africa is relatively younger compared with the RoW. Females dominate ICSRs in both Africa and the RoW.

The present study has shown that PV in Africa is growing in terms of the number of countries joining the PIDM, as well as the number of ICSRs being submitted. African reports are different from the RoW, offering the possibility of identifying important safety signals, as already mentioned by others [23]. However, the absolute numbers of ICSRs in VigiBase ${ }^{\circledR}$ are extremely low. The increasing promotion of other PV methods, including targeted spontaneous reporting and cohort event monitoring [24], could strengthen PV in Africa, while educational interventions and the use of the recent WHOInternational Society of Pharmacovigilance (ISoP) PV curriculum [25] should support standardised PV education. Both of these would both contribute toward improved ICSR reporting from Africa. The era of countries submitting just the sufficient number of ICSRs to become members of the PIDM would then be a thing of the past, especially if countries could use PV assessment tools such as the WHO PV Indicator and the MSH Indicator-based Pharmacovigilance Assessment Tool (IPAT) to evaluate their own systems and target interventions as appropriate.

\section{Limitations}

This study was a review only of the data submitted by national PV Centres to VigiBase ${ }^{\circledR}$, which may be a tiny fraction of the overall ICSRs in-country. Differences in health systems, prescriptions and disease patterns could also account for several of the differences observed between Africa and the RoW. Unpublished evidence gathered during PV country support missions in Africa suggests that the capacity for data management, including ICSR submission to VigiBase ${ }^{\circledR}$, is weak; several countries had an appreciable quantity of data stored in various ways (boxes, spreadsheets, etc.), and yet to be submitted to VigiBase ${ }^{\circledR}$. A significant proportion of ICSRs that are filled out by healthcare professionals remain with national PV centres and are not submitted to VigiBase ${ }^{\circledR}$. Each ICSR used in the analyses in this study could contain more than one ADR, hence the number of SOCs may be more than the number of ICSRs. The counting of combination products and products that are used concurrently (e.g. the use of highly active antiretroviral therapy) may lead to some products being over-represented in the count of products implicated in ICSRs. Finally, the data were analysed as present in VigiBase ${ }^{\circledR}$, meaning they contain the essential basic features of reporting (identified patient, product, ADR and reporter) without any assessment of causality or evaluation of the quality of the report. 


\section{Conclusions}

$\mathrm{PV}$ in Africa is in its developing stages, with low numbers of ICSRs reported to VigiBase ${ }^{\circledR}$. Several countries from Africa have joined the PIDM over the past few years but more than one-third of African countries are still not members of the PIDM. The characteristics of ICSRs from Africa are quite different from those of the RoW in terms of products and types of ADRs reported. African ICSRs are dominated by products for infectious diseases, including HIV/AIDS and antibiotics, while ICSRs from the RoW are mainly in relation to the following classes of products, namely $\mathrm{TNF} \alpha$ inhibitors, topical nonsteroidal anti-inflammatory drugs, immunosuppresants, selective serotonin reuptake inhibitors and statins. The dominant age groups in reports from Africa and the RoW also differ, while the gender of patients are nearly identical. With further developments and improvements in PV in Africa, the reporting and submission of ICSRs of good quality to VigiBase $^{\circledR}$ is expected to grow. This will permit signal detection and the utilisation of other proactive methods for safety surveillance of medicines, vaccines and all other medical products to improve patient safety and public health.

\section{Compliance with Ethical Standards}

Funding No external sources of funding were used for the conduct of this study, or for the writing, correction, and submission of this article.

Conflict of interest Haggar Hilda Ampadu, Jarno Hoekman, Marieke de Bruin, Shanthi Pal, Sten Olsson, Daniele Sartori, Hubert Leufkens and Alexander Dodoo have no conflicts of interest that are directly related to the content of this study.

Open Access This article is distributed under the terms of the Creative Commons Attribution-NonCommercial 4.0 International License (http://creativecommons.org/licenses/by-nc/4.0/), which permits any noncommercial use, distribution, and reproduction in any medium, provided you give appropriate credit to the original author(s) and the source, provide a link to the Creative Commons license, and indicate if changes were made.

\section{References}

1. Rovira J. Pharmaceuticals, globalization and developing countries: recent developments and challenges. Pharm Policy Law. 2002;5:7-10.

2. Pirmohamed M, Atuah KN, Dodoo AN, Winstanley P. Pharmacovigilance in developing countries. BMJ. 2007;335(7618):462.

3. Isah AO, Pal SN, Olsson S, Dodoo A, Bencheikh RS. Specific features of medicines safety and pharmacovigilance in Africa. Ther Adv Drug Saf. 2012;3(1):25-34.

4. Berhe DF, Juhlin K, Star K, Beyene KG, Dheda M, HaaijerRuskamp FM, et al. Adverse drug reaction reports for cardiometabolic drugs from sub-Saharan Africa: a study in VigiBase. Trop Med Int Health. 2015;20(6):797-806.

5. Olsson S, Pal SN, Stergachis A, Couper M. Pharmacovigilance activities in 55 low- and middle-income countries: a questionnaire-based analysis. Drug Saf. 2010;33(8):689-703.

6. Kuemmerle A, Dodoo AN, Olsson S, Van Erps J, Burri C, Lalvani PS. Assessment of global reporting of adverse drug reactions for anti-malarials, including artemisinin-based combination therapy, to the WHO Programme for International Drug Monitoring. Malar J. 2011;10:57.

7. Bakare N, Edwards IR, Stergachis A, Pal S, Holmes CB, Lindquist $\mathrm{M}$, et al. Global pharmacovigilance for antiretroviral drugs: overcoming contrasting priorities. PLoS Med. 2011;8(7):e1001054.

8. Falzon D, Hill G, Pal SN, Suwankesawong W, Jaramillo E. Pharmacovigilance and tuberculosis: applying the lessons of thioacetazone. Bull World Health Organ. 2014;92(12):918-9.

9. Lindquist M. VigiBase, the WHO global ICSR database system: basic facts. Drug Inf J. 2008;42(5):409-19.

10. Sevene E, Mariano A, Mehta U, Machai M, Dodoo A, Vilardell $\mathrm{D}$, et al. Spontaneous adverse drug reaction reporting in rural districts of Mozambique. Drug Saf. 2008;31(10):867-76.

11. Jaquet A, Djima MM, Coffie P, Kacou HD, Eholie SP, Messou E, et al. Pharmacovigilance for antiretroviral drugs in Africa: lessons from a study in Abidjan, Cote d'Ivoire. Pharmacoepidemiol Drug Saf. 2011;20(12):1303-10.

12. Aagaard L, Strandell J, Melskens L, Petersen PS, Holme Hansen E. Global patterns of adverse drug reactions over a decade: analyses of spontaneous reports to VigiBase. Drug Saf. 2012;35(12):1171-82.

13. Kiguba R, Karamagi C, Waako P, Ndagije HB, Bird SM. Recognition and reporting of suspected adverse drug reactions by surveyed healthcare professionals in Uganda: key determinants. BMJ Open. 2014;4(11):e005869.

14. Sabblah GT, Akweongo P, Darko D, Dodoo AN, Sulley AM. Adverse drug reaction reporting by doctors in a developing country: a case study from Ghana. Ghana Med J. 2014;48(4):189-93.

15. Olsson S, Pal SN, Dodoo A. Pharmacovigilance in resourcelimited countries. Expert Rev Clin Pharmacol. 2015;8(4):449-60.

16. Dodoo A, Pal SN, Falzon D, Xueref S. Pharmacovigilance for tuberculosis does not feature prominently in grant applications to the Global Fund to fight AIDS, tuberculosis and malaria. Drug Saf. 2010;33(10):924.

17. Strengthening Pharmaceutical Systems (SPS). Supporting pharmacovigilance in developing countries: the systems perspective. Submitted to the U.S. Agency for International Development by the SPS Program. Arlington (VA): Management Sciences for Health; 2009.

18. Ruud KW, Srinivas SC, Toverud EL. Addressing gaps in pharmacovigilance practices in the antiretroviral therapy program in the Eastern Cape Province, South Africa. Res Soc Adm Pharm. 2010;6(4):345-53.

19. Ruud KW, Srinivas SC, Toverud EL. Knowledge of HIV and its treatment among health care providers in South Africa. Int J Clin Pharm. 2014;36(2):352-9.

20. Boutayeb A. The double burden of communicable and noncommunicable diseases in developing countries. Trans $\mathrm{R}$ Soc Trop Med Hyg. 2006;100(3):191-9.

21. Bygbjerg IC. Double burden of noncommunicable and infectious diseases in developing countries. Science. 2012;337(6101):1499-501.

22. Oni $\mathrm{T}$, Unwin $\mathrm{N}$. Why the communicable/non-communicable disease dichotomy is problematic for public health control strategies: implications of multimorbidity for health systems in an era of health transition. Int Health. 2015;7(6):390-9.

23. Ndagije H, Nambasa V, Namagala E, Nassali H, Kajungu D, Sematiko G, et al. Targeted spontaneous reporting of suspected 
renal toxicity in patients undergoing highly active anti-retroviral therapy in two public health facilities in Uganda. Drug Saf. 2015;38(4):395-408.

24. Pal SN, Dodoo A, Mantel A, Olsson S. The world medicines situation 2011. Pharmacovigilance and safety of medicines. WHO/EMP/MIE/201127. 2011.
25. Beckmann J, Hagemann U, Bahri P, Bate A, Boyd IW, Dal Pan GJ, et al. Teaching pharmacovigilance: the WHO-ISoP core elements of a comprehensive modular curriculum. Drug Saf. 2014;37(10):743-59. 